\title{
Mortality risks, education and child labor*
}

\author{
Fernanda Estevan $^{\dagger} \quad$ Jean-Marie Baland ${ }^{\ddagger}$
}

February 20, 2007

\begin{abstract}
In this paper, we investigate the role of young adult mortality on child labor and educational decisions. We argue that mortality risks are a major source of risks in returns to education in developing countries. We show that, in the absence of appropriate insurance mechanisms, the level of child labor is inefficient, but it can be too high or too low. It is too high when parents are not very altruistic and anticipate positive transfers from their children in the future. Uncertain returns to education, endogenous mortality or imperfect capital markets unambiguously increase child labor. When the level of child labor is inefficiently high, we also show that a cash transfer conditional on child's schooling can always restore efficiency regarding child labor.
\end{abstract}

*This paper is part of Fernanda's Phd thesis. For useful discussions and comments, we would like to thank Guido Friebel, Jean Hindriks, Pierre Pestieau, and Hosny Zoabi, as well as participants to seminars given in Public Economics Meeting at CORE, CORE-IDEI Conference in Public Economics (Toulouse), CRED Workshop, and Journées de l'AFSE 2005, two anonymous referees, and the editor for their insightful comments on former drafts of this paper. We would like to thank the MacArthur network on Inequality and Economic Performance and the CRED for financial support. This work is part of the Belgian Program on Inter-University Poles of Attraction initiated by the Belgian State, Prime Minister's office, Science Policy Programming and of the Action de Recherches Concertees (Namur).

${ }^{\dagger}$ Corresponding author: Department of Economics, CORE, Catholic University of Louvain 34, Voie du Roman Pays - 1348 - Louvain la Neuve, Belgium - Phone: +32.10.47.83.06 - Fax: +32.10.47.43.01 E-mail address: estevan@core.ucl.ac.be.

${ }^{\ddagger}$ Department of Economics, CRED, University of Namur. 


\section{Introduction}

Child labor is a pressing and important social issue. According to the ILO, about one fifth of all children between 5 and 14 were considered as working in the world in 2000. Child labor is highly concentrated in developing countries, with $60 \%$ of all working children living in the Asian-Pacific region. The highest proportion of working children is however found in Sub-Saharan Africa, with an average $29 \%$ of children working.

In a seminal paper, Basu and Van (1998) show that, if adult and child labor are substitutes and parents send their children to work only when the family is poor, multiple equilibria can exist. This gives scope for policy interventions such as a ban that moves the economy from a 'bad' equilibrium, where both children and adults are working for low wages, to a good one, where children do not work and wages are high.

Another approach attempts to understand how child labor can arise as the rational decision by parents who take into account the trade-off between child labor and schooling. In this perspective, there are two possible explanations for the incidence of child labor. The first possibility is that private returns from education are not high enough. This view is apparently contradicted by several empirical studies, for instance, Duflo (2001) who shows that one additional year of schooling increases earnings by $8 \%$ in Indonesia. ${ }^{1}$

The second possibility is that several constraints force parents to take inefficient decisions with respect to child labor. Baland and Robinson (2000) explicitly consider the trade-off between child labor and the accumulation of human capital. In a model in which parents are fully altruistic with respect to their children, they show that an inefficiently high level of child labor may arise when the parents leave their children no bequests or when capital markets are imperfect. ${ }^{2}$ With perfect capital markets and positive bequests, the parents always choose the privately efficient level of child labor, as they perfectly internalize the negative impact of child labor on their children future earning ability. This mechanism requires that parents perfectly anticipate returns to education.

However, education is also a risky investment (see e.g., Becker, 1964; Levhari and Weiss, 1974). First, parents do not observe perfectly their children's abilities

\footnotetext{
${ }^{1}$ For a survey of the major studies of education returns from several countries, see Ashenfelter et al. (1999). The United States stand out by presenting higher returns to education in the last two decades than most other countries.

${ }^{2}$ The impact of liquidity constraints on child labor was investigated in Edmonds (2006). Using South African data, he analyzes the effect of anticipated pension income on child labor and schooling decisions. He shows that, once households become eligible for the pension, child labor declines and schooling increases, suggesting the presence of liquidity constraints.
} 
nor the quality of schooling. Second, future labor market conditions are subject to unpredictable events. We discuss these types of risk in more details in Section 5.

High mortality rates among young adults constitute a third source of uncertainty as they directly affect returns to education. ${ }^{3}$ Table 1 presents some data on life expectancy and mortality rates for selected countries.

Table 1: Demographic figures

\begin{tabular}{|l|c|c|}
\hline Country & $\begin{array}{c}\text { Life expectancy } \\
\text { at birth (years) }\end{array}$ & $\begin{array}{c}\text { Mortality rate between } \\
\text { ages } 15 \text { and } 44 \text { (per 1,000 births) }{ }^{a} \\
2003\end{array}$ \\
\hline Japan & 82.0 & 21 \\
United States & 77.4 & 38 \\
China & 71.6 & 41 \\
Indonesia & 66.8 & 84 \\
Honduras & 67.8 & 88 \\
\hline India & 63.3 & 102 \\
Senegal & 55.7 & 139 \\
Sudan & 56.4 & 166 \\
Ghana & 56.8 & 170 \\
Mali & 47.9 & 245 \\
Cameroon & 45.8 & 287 \\
\hline Cote d'Ivoire & 45.9 & 344 \\
Burkina Faso & 47.5 & 352 \\
Kenya & 47.2 & 373 \\
South Africa & 48.4 & 402 \\
Malawi & 39.7 & 484 \\
Zambia & 37.5 & 575 \\
Zimbabwe & 36.9 & 675 \\
\hline
\end{tabular}

Source: Column 1: Human Development Report (2005), United Nations, http://hdr.undp.org/reports/global/2005/; Column 2: World Health Organization Statistical Information System, World Health Organization, http://www3.who.int/whosis/menu.cfm

${ }^{a}$ The mortality rate between ages 15 and $45, q_{15-44}$, was calculated using life tables available at the World Health Organization Statistical Information System (WHOSIS) at http://www3.who.int/whosis/menu.cfm. By definition, $q_{15-44}=\frac{I_{15}-I_{45}}{I_{15}}$, where $I_{X}$ is an imaginary number of survivors from an initial 100,000 imaginary births, assuming these imaginary births were to experience the same mortality rates as those underlying the current life table. Thus $I_{X}$ bears no relation to the actual number of individuals aged $\mathrm{x}$ in the real population.

The table illustrates the large discrepancies in life expectancy between developing and developed countries, but also among developing countries. In Asia or Latin America, life expectancy is on average 10 years lower than in a developed economy,

\footnotetext{
${ }^{3}$ Razin (1976) focuses on the advantage of physical capital compared to human capital, as the latter is not transferable, in the presence of premature mortality.
} 
but 20 to 30 years higher than in most African countries. Infant and under-five mortality rates certainly explain part of these differences, but they are not directly relevant to our question. More interesting is the evidence on mortality rates between ages 15 and 44, that is, after an individual received most of his education. In Africa, the probability of dying between 15 and 44 lies between $15 \%$ and $70 \%$, compared to less than $10 \%$ in other developing countries (and less than $5 \%$ in developed countries).

High mortality rates have a large impact on the expected returns to education. To see this, assume that the United States and South Africa have the same return per year of schooling equal to $10 \%$. When one takes into account the possible early death of an educated person, the expected return from education in the US is $9.6 \%$, while in South Africa it is only 6\%. To put it differently, to reach the same expected return of $9.6 \%$ per year of education, the return to education must be equal to $10 \%$ in the US, but to $16 \%$ in South Africa. These differences must have a large impact on education decisions and child labor across countries. Figure 1 below illustrates the positive correlation existing between child labor and young adult mortality in a sample of 126 countries. Figure 2 presents the negative correlation that exists between net enrollment and child labor in the same sample.

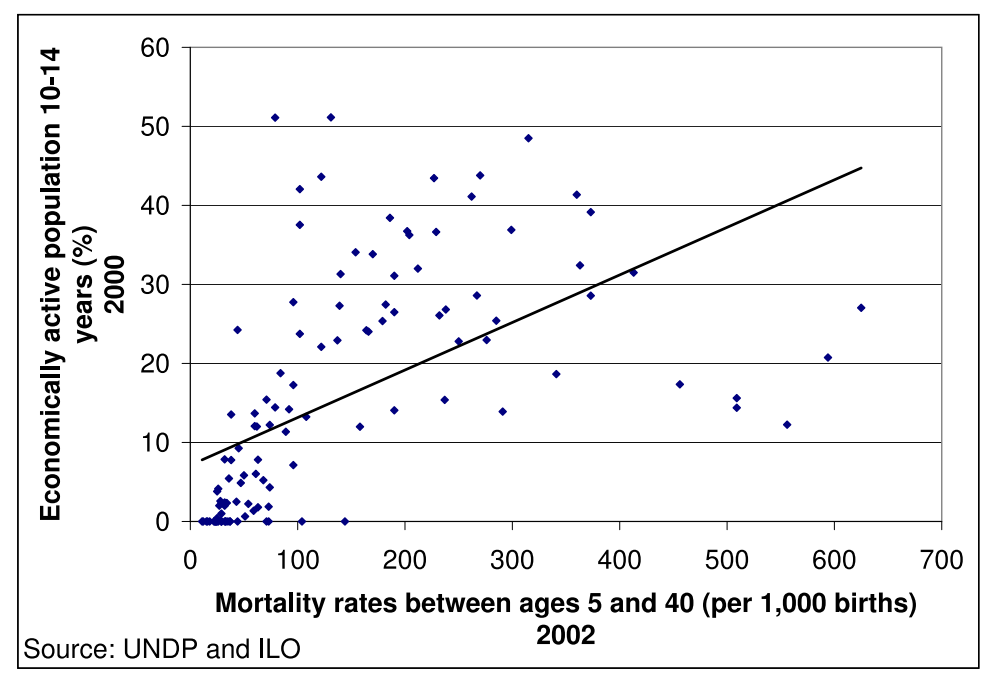

Figure 1: Mortality rates vs. Child labor

In this paper we investigate the relationship between young adult mortality and child labor. We present a modified version of Baland and Robinson (2000) to allow for children's uncertain lifetime by introducing the possibility of premature death. We show that, even when capital markets are perfect and intergenerational transfers are positive, the level of child labor is inefficient. It is inefficiently high when parents are not too altruistic and anticipate positive transfers from their children in the 


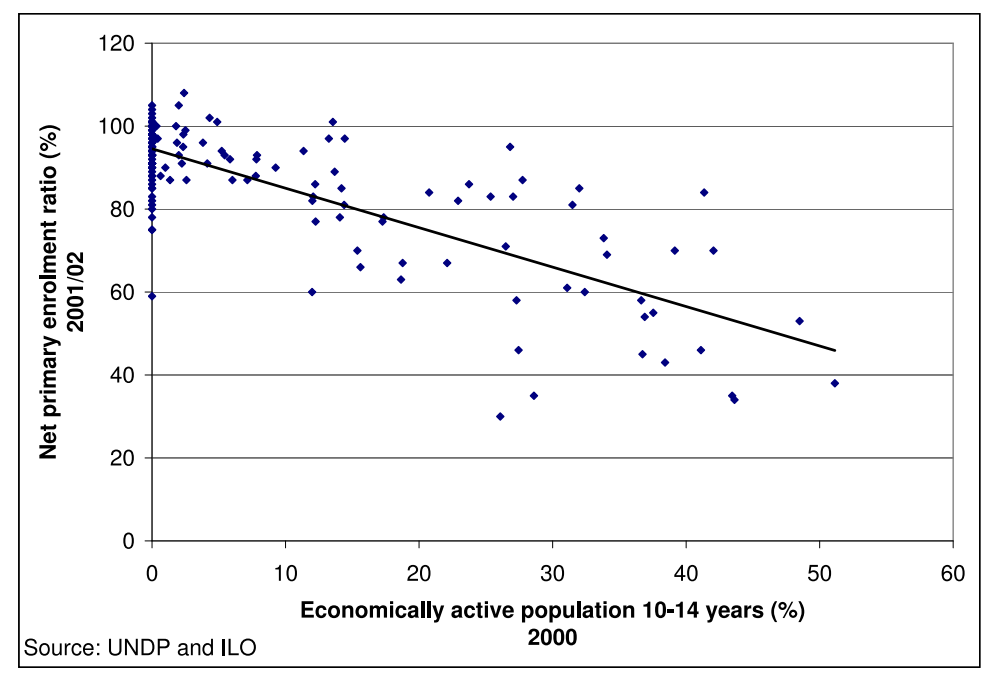

Figure 2: Net enrollment vs. Child labor

future, as in the old-age security model. This is because, given the possible death of their child, they tend to favor a certain investment, such as saving, to an uncertain one, such as human capital. However, we also show that child labor is inefficiently low when parents anticipate to make positive future transfers to their children. Indeed, with the possible death of their child, parents prefer an investment that is contingent on their child being alive, such as education, to one which is not, such as savings. In this respect, it is striking that Sub-Saharan Africa presents the highest young mortality rates, the largest proportion of working children as well as a generalized practice of large scale transfers from young working adults to their parents (see e.g., Caldwell and Caldwell, 1987).

Eswaran (2000) presents an old-age security model, where parents simultaneously decide how many children to have and whether to send them to school or to work, taking into account that some of them will die before adulthood. The combination of high mortality rates with lack of access to capital markets induces parents to have many children to ensure that enough will survive to provide them with oldage support. Child labor is then used to maintain income in large families. Our paper stresses another mechanism, by positing exogenous fertility and perfect capital markets, and focussing on the imperfections of the insurance market (against child mortality). ${ }^{4}$ Moreover, we also show that while child labor is likely to be too high in the old-age security model, it can also be too low when parental altruism is strong. ${ }^{5}$

\footnotetext{
${ }^{4}$ Our results easily generalize to a situation where fertility is endogenous.

${ }^{5}$ Strulik (2004) builds a growth model combining fertility, child mortality, child labor and education to analyze the impact of child mortality on economic growth. However, human capital does not enter explicitly into the utility function of parents, and there is no inter-generational transfers, while they play a crucial role in our results.
} 
Closer to this paper, Pouliot (2006) introduces uncertainty in returns to human capital into Baland and Robinson (2000). He shows that, if the return to education is a continuous random variable, the level of child labor is inefficiently high in the absence of insurance markets, even when bequests and savings are interior. Parents then always prefer to increase child labor at the expense of education, as the latter is now a risky investment. We show that this result depends crucially on the type of uncertainty that is being considered. When young adult mortality is introduced, the issue of contingent transfers becomes critical. Indeed, the main difference between uncertain returns and mortality risks is that the first one can only affect directly schooling decisions, while the other also affects transfers and saving decisions. In a one period model with no savings and intergenerational transfers, the impact of both types of uncertainty would be identical. Also, as an explanation for child labor, uncertainty in returns to education should be more pronounced in developing countries than in developed countries. Unfortunately, the evidence available does not suggest that this is the case. We return to this issue in more details in Section 5 .

This paper is organized as follows. In Section 2, we present the basic model, the results of which are presented in Section 3. In Section 4, we generalize our main results to the case where parents can decide to incur health expenditures to reduce mortality risks, and in Section 5, to the case where returns to education are intrinsically uncertain. Section 6 discusses possible policy interventions, and the last Section concludes.

\section{The Basic Model}

We consider two periods, $t=1,2$. In each period, the production technology is such that one unit of labor produces one unit of the numeraire good. The wage rate is equal to 1 . There are $L_{p}$ parents who supply $A$ efficiency units of labor in each period. Each parent has one child. In the first period, the parent decides the amount of time his child spends working, $l_{c} \in[0,1]$, where $\left(1-l_{c}\right)$ represents the time she spends at school. While the assumption of perfect substitution between schooling and child labor is made for analytical convenience, it is also aimed to reflect the trade-off illustrated by Figure 2 above where the time spent at school, particularly beyond the first years of primary school, reduces the amount of time available for productive activities.

In the first period, the parent also decides the amount he consumes, $c_{1}$, and the amount he chooses to save, $s$. The child takes no decision in period 1 . We consider that capital markets are perfect, so that $s$ can be positive or negative, and we assume 
that the discount rate and the interest rate are both equal to zero. In the end of Section 3, we discuss the implications of imperfect capital markets where parents can save but not borrow.

While all parents live in the second period ${ }^{6}$, some children may die at the end of period 1 with probability $(1-p)$. We assume that $p$, the probability that a child lives in period 2 , is exogenous. In period 2 , if she survived, the child is now an adult and supplies $h\left(1-l_{c}\right)$ efficiency units of labor. $h\left(1-l_{c}\right)$ represents the human capital she possesses in period 2 if she worked $l_{c}$ units of time in period 1 . An increase in schooling increases the amount of human capital, but at a decreasing rate, that is, $h^{\prime}\left(1-l_{c}\right)>0$ and $h^{\prime \prime}\left(1-l_{c}\right)<0$. We also assume $h(0)=1, h^{\prime}(0)=\infty$, and $h^{\prime}(1)=0$ (which imply that the optimal value of $l_{c}$ is interior). In period 2 , the child, when alive, chooses the amount she consumes, $c_{c}$, and the amount $\tau$ she transfers to her parent. Each parent chooses the amount $b$ he gives to his child. If the child dies at the end of period 1 , no transfers can be made, so that $b=\tau=0$. Transfers are positive or nil: $b \geq 0, \tau \geq 0$.

We first consider the situation under which there is a perfect insurance market. The only risk faced by a parent is the possibility that his child dies at the end of period 1 , in which case he cannot, in period 2 , give or receive transfers. The insurance contract is such that if $P$ is the premium a parent decides to pay in period 1 , he receives an amount $I=P /(1-p)$ in period 2 if his child dies, and 0 if not. In period 1 , the parent faces the following budget constraint:

$$
c_{1}=A+l_{c}-s-(1-p) I
$$

where $c_{1}$, his consumption in period 1 , is equal to the household labor earnings, $A+l_{c}$, minus the amount he saves, $s$, and the insurance premium, $(1-p) I$ (for simplicity, we assume that children do not consume in period 1 ). In period 2 , the parent's budget constraint differs depending on whether his child died at the end of period 1 or not. We let $c_{2}^{a}$ and $c_{2}^{d}$ denote parental consumption in period 2 if his child is alive and not alive, respectively. If the child is alive, the parent's budget constraint is:

$$
c_{2}^{a}=A+s-b+\tau
$$

and if the child died at the end of period 1, the parent's budget constraint in period 2 is:

$$
c_{2}^{d}=A+s+I
$$

\footnotetext{
${ }^{6}$ Note that the possibility that parents die after the first period complicates substantially the analysis and yields more ambiguous results.
} 
Given his budget constraints, a parent chooses $l_{c}, s$, and $(1-p) I$ in period 1 and $b$ in period 2 if his child is alive to maximize the following utility function:

$$
W_{p}=U\left(c_{1}\right)+\left[p U\left(c_{2}^{a}\right)+(1-p) U\left(c_{2}^{d}\right)\right]+p \delta W_{c}
$$

where $W_{c}$ represents the child's utility in period 2 , if she is alive, and $\delta$ measures parental altruism.

In period 2 , if she is alive, the child's budget constraint is:

$$
c_{c}=h\left(1-l_{c}\right)+b-\tau
$$

and she chooses $\tau$ to maximize:

$$
W_{c}=V\left(c_{c}\right)+\lambda\left[U\left(c_{2}^{a}\right)+\delta W_{c}\right]=\frac{V\left(c_{c}\right)+\lambda U\left(c_{2}^{a}\right)}{1-\delta \lambda}
$$

where $\lambda$ measures filial altruism.

Replacing (6) into (4), the parent's utility function can be rewritten as:

$$
W_{p}=U\left(c_{1}\right)+p \frac{U\left(c_{2}^{a}\right)}{1-\delta \lambda}+(1-p) U\left(c_{2}^{d}\right)+p \frac{\delta V\left(c_{c}\right)}{1-\delta \lambda}
$$

We assume that $U$ and $V$ are both strictly increasing, strictly concave, and twice continuously differentiable. To avoid unbounded hall-of-mirror effects, we assume that $\delta<1$ and $\lambda<1$ so that the mutual altruism multiplier is well defined: $1-\delta \lambda>$ 0 .

The first-order conditions with respect to child labor, savings, insurance, and parental transfers are respectively:

$$
\begin{aligned}
& U^{\prime}\left(c_{1}\right)+p \frac{U^{\prime}\left(c_{2}^{a}\right)}{1-\delta \lambda} \frac{d \tau}{d l_{c}}=p \frac{\delta V^{\prime}\left(c_{c}\right)}{1-\delta \lambda}\left[h^{\prime}\left(1-l_{c}\right)+\frac{d \tau}{d l_{c}}\right] \quad \text { and } \quad \tau>0 \\
& U^{\prime}\left(c_{1}\right)=p \frac{\delta V^{\prime}\left(c_{c}\right)}{1-\delta \lambda} h^{\prime}\left(1-l_{c}\right) \quad \text { and } \quad \tau=0 \\
& U^{\prime}\left(c_{1}\right)+p \frac{\delta V^{\prime}\left(c_{c}\right)}{1-\delta \lambda} \frac{d \tau}{d s}=p \frac{U^{\prime}\left(c_{2}^{a}\right)}{1-\delta \lambda}\left[1+\frac{d \tau}{d s}\right]+(1-p) U^{\prime}\left(c_{2}^{d}\right) \quad \text { and } \quad \tau>0 \\
& U^{\prime}\left(c_{1}\right)=p \frac{U^{\prime}\left(c_{2}^{a}\right)}{1-\delta \lambda}+(1-p) U^{\prime}\left(c_{2}^{d}\right) \quad \text { and } \quad \tau=0 \\
& U^{\prime}\left(c_{1}\right)=U^{\prime}\left(c_{2}^{d}\right) \\
& U^{\prime}\left(c_{2}^{a}\right)=\delta V^{\prime}\left(c_{c}\right) \text { and } b>0 \\
& U^{\prime}\left(c_{2}^{a}\right)>\delta V^{\prime}\left(c_{c}\right) \text { and } b=0
\end{aligned}
$$


Note that the parent anticipates the impact of his decisions in the first period on the amount of filial transfers, when positive. ${ }^{7}$ Equation (12) states that a parent chooses $(1-p) I$ so as to equalize his first period marginal utility to his second period marginal utility if his child dies.

Similarly, the first-order condition with respect to filial transfers, $\tau$, are given by:

$$
\begin{array}{r}
V^{\prime}\left(c_{c}\right)=\lambda U^{\prime}\left(c_{2}^{a}\right) \text { and } \tau>0 \\
V^{\prime}\left(c_{c}\right)>\lambda U^{\prime}\left(c_{2}^{a}\right) \text { and } \tau=0
\end{array}
$$

Equations (13) and (15) cannot hold simultaneously. The non-negativity constraints on transfers allow us to distinguish between three different situations: (1) Parental transfers, with $b>0$ and $\tau=0$; (2) Filial transfers, with $b=0$ and $\tau>0$; and (3) No transfers, with $b=\tau=0$, in which both the parent and the child choose to make no transfers. Lemma 1 establishes the existence of these three cases.

Lemma 1. If $\delta \lambda<1$, there always exists $[\delta, \lambda]$ such that filial transfers are positive, $\left[\delta^{\prime}, \lambda^{\prime}\right]$ such that parental transfers are positive, and $\left[\delta^{\prime \prime}, \lambda^{\prime \prime}\right]$ such that intergenerational transfers are nil.

Proof. Consider the case in which $\tau>0$. For all feasible values of $c_{2}^{a}$ and $c_{c}$, there is a $\lambda$ high enough and a $\delta$ low enough such that filial transfers are positive, that is,

$$
\begin{aligned}
& \lambda>\frac{V^{\prime}(h(0))}{U^{\prime}(2 A+1)} \\
& \delta<\frac{U^{\prime}(2 A+1)}{V^{\prime}(h(0))}
\end{aligned}
$$

Note that $2 A+1$ corresponds to the highest possible parental income in period 2, as in this case, the child did not go to school and the parent saved all his income in period 1. Similarly, $h(0)$ corresponds to the level of human capital that the child will have if she did not receive any education. This condition implies that even if parents transfer all their income in period 2, children with zero education will still be willing to transfer strictly positive amounts of income to their parents.

The proof for the case of parental transfers and no transfers can be obtained with a similar argument.

Typically, transfers are nil when $\delta$ and $\lambda$ are both small enough, parental transfers are positive if $\delta$ is high and $\lambda$ is low, and filial transfers are positive if $\lambda$ is high and

\footnotetext{
${ }^{7}$ There is no impact of the insurance premium, as this gives rise to benefits for the parent only if his child dies, and transfers are therefore nil. Parental transfers have no impact either as they are contemporaneous to filial transfers.
} 
$\delta$ is low. Note that transfers are also nil when $\delta$ and $\lambda$ are both high and the consumption levels of the parent and the child are close enough.

\section{Main results}

We first discuss the equilibrium obtained when the insurance market is perfect. If transfers are not nil, the parent fully internalizes the impact of his decision regarding child labor on the earning ability of his child in period 2. As a result, he equalizes the expected marginal benefit of schooling, $p h^{\prime}\left(1-l_{c}^{e}\right)$, to 1 , its cost in terms of lost labor income in period 1. This corresponds to the Pareto efficient level of child labor, which is decreasing in the probability of survival. This result is stated in Proposition 1.

Proposition 1. With perfect insurance markets, child labor is efficient iff transfers are not nil. The efficient level of child labor is such that:

$$
p h^{\prime}\left(1-l_{c}^{e}\right)=1
$$

Proof. We propose here a brief sketch of the proof. Equation (18) obtains by combining equations (9), (11), (12), and (13) when parental transfers are positive. When filial transfers are positive, differentiating (15) with respect to $l_{c}$ and $s$ we obtain:

$$
\begin{aligned}
\frac{d \tau}{d l_{c}} & =\frac{-h^{\prime}\left(1-l_{c}\right) V^{\prime \prime}\left(c_{c}\right)}{\lambda U^{\prime \prime}\left(c_{2}^{a}\right)+V^{\prime \prime}\left(c_{c}\right)} \\
\frac{d \tau}{d s} & =\frac{-\lambda U^{\prime \prime}\left(c_{2}^{a}\right)}{\lambda U^{\prime \prime}\left(c_{2}^{a}\right)+V^{\prime \prime}\left(c_{c}\right)}
\end{aligned}
$$

Then by combining equations (8), (10), (12), (15), (19), and (20) we obtain the result. To show that this is efficient, one has to show that no profitable contract can be made between the parent and the child such that the latter would be ready to pay for a marginal increase in her education more than its opportunity cost to her parent, which is exactly equal to 1 . The inefficiency of parental decisions when transfers are nil can be proven following Baland and Robinson (2000). Thus, with $b=\tau=0$, one obtains easily that $p h^{\prime}\left(1-l_{c}^{e}\right)=\frac{(1-\delta \lambda) U^{\prime}\left(c_{1}\right)}{\delta V^{\prime}\left(c_{c}\right)}=\frac{U^{\prime}\left(c_{2}^{a}\right)}{\delta V^{\prime}\left(c_{c}\right)}>1$.

If the insurance market is absent, equation (12) does not hold as the parent has no more access to an insurance contract. We first describe the equilibrium level of child labor that prevails in the three different situations of parental transfers, filial transfers and no transfers. When filial transfers are positive, using equation (19), 
equation (8) can be rewritten as follows:

$$
U^{\prime}\left(c_{1}\right)=p h^{\prime}\left(1-l_{c}\right) \frac{\lambda U^{\prime \prime}\left(c_{2}^{a}\right) \delta V^{\prime}\left(c_{c}\right)+V^{\prime \prime}\left(c_{c}\right) U^{\prime}\left(c_{2}^{a}\right)}{(1-\delta \lambda)\left(\lambda U^{\prime \prime}\left(c_{2}^{a}\right)+V^{\prime \prime}\left(c_{c}\right)\right)}
$$

Using equation (20), equation (10) becomes:

$$
U^{\prime}\left(c_{1}\right)=(1-p) U^{\prime}\left(c_{2}^{d}\right)+p \frac{\lambda U^{\prime \prime}\left(c_{2}^{a}\right) \delta V^{\prime}\left(c_{c}\right)+V^{\prime \prime}\left(c_{c}\right) U^{\prime}\left(c_{2}^{a}\right)}{(1-\delta \lambda)\left(\lambda U^{\prime \prime}\left(c_{2}^{a}\right)+V^{\prime \prime}\left(c_{c}\right)\right)}
$$

Combining those two equations together to eliminate the term in $U^{\prime}\left(c_{1}\right)$, one obtains:

$$
p h^{\prime}\left(1-l_{c}^{*}\right)=p+(1-p) \frac{\lambda U^{\prime \prime}\left(c_{2}^{a}\right)+V^{\prime \prime}\left(c_{c}\right)}{\delta \lambda^{2} U^{\prime \prime}\left(c_{2}^{a}\right)+V^{\prime \prime}\left(c_{c}\right)} \frac{U^{\prime}\left(c_{2}^{d}\right)}{\frac{U^{\prime}\left(c_{2}^{a}\right)}{1-\delta \lambda}}
$$

which characterizes the equilibrium level of child labor when filial transfers are positive and insurance markets are missing. When parental transfers are positive, combining equations (9), (11) and (13), the equilibrium level of child labor is given by:

$$
p h^{\prime}\left(1-l_{c}^{*}\right)=p+(1-p) \frac{U^{\prime}\left(c_{2}^{d}\right)}{\frac{U^{\prime}\left(c_{2}^{a}\right)}{1-\delta \lambda}}
$$

The additional term in the expression (21) reflects the anticipation by the parent of the impact of his decisions on filial transfers. Finally, in the absence of transfers, we obtain by combining equations (9) and (11):

$$
p h^{\prime}\left(1-l_{c}^{*}\right)=p \frac{U^{\prime}\left(c_{2}^{a}\right)}{\delta V^{\prime}\left(c_{c}\right)}+(1-p) \frac{U^{\prime}\left(c_{2}^{d}\right)}{\frac{\delta V^{\prime}\left(c_{c}\right)}{1-\delta \lambda}}
$$

In all these situations, the equilibrium level of child labor is monotonically increasing with mortality rates. This is expressed in the following proposition:

Proposition 2. With or without perfect insurance markets, an increase in child mortality increases the equilibrium level of child labor.

Proof. With perfect insurance, this result is straightforward by (18). Without perfect insurance, a proof in the case of parental transfers is presented in the Appendix A.

The intuition for this result is straightforward. An increase in mortality rates lowers the expected return to education, which induces parents to reduce their investment in education and increase the level of child labor. ${ }^{8}$

\footnotetext{
${ }^{8}$ In a recent paper, Hazan and Zoabi (2006) propose a model of education with endogenous fertility. When fertility and education are decided simultaneously, an increase in longevity has no impact on the optimal level of education, as it does not affect the marginal rate of substitution between the quality and the quantity of children. This argument does not apply here because the parents' savings and transfer decisions are contingent on the child's probability of survival.
} 
We now show that the impact of mortality on child labor goes beyond its direct impact on the expected returns to education. Indeed, in the absence of insurance, the uncertainty about child survival leads parents to choose inefficient levels of child labor. This holds even if capital markets are perfect and transfers are not nil. ${ }^{9}$ The impact of mortality risks on child labor, however, critically depends on the direction of intergenerational transfers.

\subsection{Case 1: Filial transfers}

We focus on the situation where filial transfers are positive, which corresponds to the old-age security model. We obtain:

Proposition 3. In the absence of insurance markets and with positive filial transfers $(\tau>0)$, the equilibrium level of child labor is inefficient. It is too high if $\delta \lambda<\frac{1}{2}$, and it is too low for $\delta \lambda \rightarrow 1$.

Proof. First note that with positive filial transfers, $c_{2}^{a}>c_{2}^{d}$, so that $U^{\prime}\left(c_{2}^{d}\right)>U^{\prime}\left(c_{2}^{a}\right)$. Moreover, $U^{\prime}\left(c_{2}^{a}\right)>\delta V^{\prime}\left(c_{c}\right)$ by (14). If $\delta \lambda<\frac{1}{2}$, equation (21) implies:

$$
p h^{\prime}\left(1-l_{c}^{*}\right)>1
$$

In contrast, if $\delta \lambda \rightarrow 1$, this result no longer holds and the equilibrium level of child labor is inefficiently low.

This result is surprising at first sight, since one would believe that, in the absence of insurance, parents would rather choose the "certain" income (i.e., child labor) at the expense of the uncertain one (i.e., child education). The above proposition shows that this intuition does not always hold. As it can be seen from equation (21), two opposite effects determine the equilibrium level of child labor. The insurance effect, represented by the term $\frac{\lambda U^{\prime \prime}\left(c_{2}^{a}\right)+V^{\prime \prime}\left(c_{c}\right)}{\delta \lambda^{2} U^{\prime \prime}\left(c_{2}^{a}\right)+V^{\prime \prime}\left(c_{c}\right)} \frac{U^{\prime}\left(c_{2}^{d}\right)}{U^{\prime}\left(c_{2}^{a}\right)}$, is related to the idea that parents prefer a certain income to the risky investment in education. More precisely, while expecting filial transfers, a parent attempts to reduce the difference between his two utility flows in period 2 by reducing education (and hence filial transfers) and increasing savings. The term $1-\delta \lambda$ represents the altruism effect which operates in the opposite direction. Indeed, under two-sided altruism, a parent gives more weight to his own utility when his child is alive. This induces him to invest more in education. If $\delta \lambda$ is low enough, the strategic effect dominates the altruism effect, and the level of child labor is inefficiently high. ${ }^{10}$

\footnotetext{
${ }^{9}$ When transfers are nil, the level of child labor is inefficient even in the presence of perfect insurance market, as discussed in Proposition 1. To properly identify the impact of the absence of an insurance market, we thus need to focus on situations where transfers are not nil.

${ }^{10}$ An alternative modelling strategy could be to assume that children's utility is defined over the
} 


\subsection{Case 2: Parental transfers}

Suppose that parental transfers are strictly positive: $b>0$. We obtain:

Proposition 4. In the absence of insurance markets and with positive bequests $(b>0)$, the equilibrium level of child labor is inefficiently low.

Proof. With positive parental transfers, $c_{2}^{a}<c_{2}^{d}$. Equation (22) then implies:

$$
p h^{\prime}\left(1-l_{c}^{*}\right)<1
$$

Once again, the result is counter-intuitive. When parental transfers are positive, child labor is too low. Actually, with positive bequests, the insurance effect now works in the same direction as the altruism effect. The reason for this is that a parent has two ways to make transfers to his child: to reduce her workload and increase her human capital and thereby raise her future income, or to increase her workload, save and then transfer in period 2. In the latter scenario, however, if the child dies, the parent is left with too much income in period 2. As a result, the parent chooses to invest more in the contingent transfer, which is education.

\subsection{Case 3: No transfers}

In the absence of an insurance market when no transfers are made in equilibrium, the arguments used in the two last propositions do not apply. Indeed, as no transfers are made in period 2, the consumption level of the parent is the same, whether her child is still alive or not. The insurance effect does not apply here. However, in the absence of transfers, parents do not internalize properly the impact of their educational decisions either. As a careful examination of equation (23) reveals, when altruism is low on both sides, the altruism effect is weak, and parents internalize little of the benefits of education, so that child labor is too high. By contrast, when altruism is high on both sides, child education may be too high.

\subsection{Case 4: Imperfect capital markets}

So far, we assumed capital markets to be perfect. We now consider the implications of this assumption by assuming that parents can save but cannot borrow. We denote the equilibrium level of child labor in this setting $l_{c}^{i}$.

lifetime utility of their parents, $W_{p}$, instead of $U\left(c_{2}^{a}\right)$. In this case, the altruism effect disappears and child labor is too high under filial transfers, irrespective of the value of $\delta \lambda$. However, this conception of filial altruism implies that a child has preferences on her parents'utility even if she is not alive, which appears inconsistent. 
If savings are at the corner, the first-order condition with respect to $s$ (see equations (10) and (11)) becomes:

$$
U^{\prime}\left(c_{1}\right)>p \frac{U^{\prime}\left(c_{2}^{a}\right)}{1-\delta \lambda}+(1-p) U^{\prime}\left(c_{2}^{d}\right)
$$

since $s=0$. One obtains by combining equations (9), (13), and (25) (in the case of parental transfers) or equations (8), (15), (19), (20), and (25) (in the case of filial transfers):

$$
p h^{\prime}\left(1-l_{c}^{i}\right)>p h^{\prime}\left(1-l_{c}^{*}\right) .
$$

The equilibrium level of child labor is always higher under imperfect capital markets.

This result is similar to the one obtained by Baland and Robinson (2000). Since parents cannot transfer income to the present by borrowing, they do so by increasing child labor beyond its efficient level. We showed above that with parental transfers or with filial transfers and $\delta \lambda \rightarrow 1$, child labor is inefficiently low. Imperfect capital markets may thus help to reduce this inefficiency (even though the resulting equilibrium level of child labor can now be too low or too high). In the case of filial transfers with $\delta \lambda<\frac{1}{2}$, capital market imperfections further increase the level of child labor, making it even more inefficient.

\section{Endogenous Probability of Survival}

So far, mortality rates were exogenous. However, early investments by parents in the health of their children have a direct impact on their mortality risks, and can thereby affect our main result by modifying the incentives for parents to invest in their child's education. In this section, we extend our analysis to the case where the probability of survival is endogenous. In period 1 , parents can invest an amount $m$ in their child's health, which reduces their probability of mortality: $p^{\prime}(m)>0$. We also assume $p^{\prime \prime}(m)<0$, and $\lim _{m \rightarrow 0} p^{\prime}(m)=\infty$. The parents' first period budget constraint becomes:

$$
c_{1}=A+l_{c}-s-m
$$

and the parents' expected utility function becomes:

$$
W_{p}=U\left(c_{1}\right)+\frac{p(m) U\left(c_{2}^{a}\right)}{1-\delta \lambda}+(1-p(m)) U\left(c_{2}^{d}\right)+\frac{p(m) \delta V\left(c_{c}\right)}{1-\delta \lambda}
$$


We first discuss the level of health expenditures. When parents maximize their expected utility with respect to $m$, the first-order condition can be written as:

$$
U^{\prime}\left(c_{1}\right)=p^{\prime}(m)\left(\frac{U\left(c_{2}^{a}\right)}{1-\delta \lambda}-U\left(c_{2}^{d}\right)+\frac{\delta V\left(c_{c}\right)}{1-\delta \lambda}\right)
$$

where the marginal cost of one unit of health expenditure is given in the left-hand side and the marginal benefit on the right-hand side of the equality. In this expression, the parents internalize the impact of a reduced mortality rate on their children welfare through their altruism parameter only. They thereby neglect the impact on the utility of their children per se. Thus, if the expected utility of a child is given by $p(m) W_{c}=p(m) \frac{V\left(c_{c}\right)+\lambda U\left(c_{2}^{a}\right)}{1-\delta \lambda}$, the marginal benefit of one unit of health expenditure for the child is given by $p^{\prime}(m) \frac{V\left(c_{c}\right)+\lambda U\left(c_{2}^{a}\right)}{1-\delta \lambda}$. Since this term is missing from the right-hand side of equation (29), investments in health are typically sub-optimal. In other words, for any parental decision in health expenditures as given by (29), there always exists a transfer scheme (a contract) from children to parents which increases the welfare of all agents. The sub-optimality underlined here directly follows from our formulation of reciprocal altruism, which leaves some room for intergenerational externalities. An alternative approach to dynastic altruism can be proposed where all externalities are internalized and mortality decisions are then efficient (i.e. they cannot be improved upon by intergenerational contracts). ${ }^{11} 12$

More importantly, all the results presented in Section 3 are left unchanged by this extension of the model (the steps of the proofs are identical), but with a proviso: the equilibrium level of child labor may be too high or too low with respect to the level defined by: $p(m) h^{\prime}\left(1-l_{c}\right)=1$. The efficiency implications of these results have to be rephrased carefully however, since the survival probability $p(m)$ decided by the parent is inefficiently low. Thus, in the case of parental transfers, the lack of insurance markets tends to lower the level of child labor, but the lower survival rates tend to make it too high, so that the net effect is ambiguous. More interestingly perhaps, with filial transfers and $\delta \lambda<\frac{1}{2}$, the equilibrium level of child labor is unambiguously too high: the inefficiency in health decisions and the inefficiency in education decision reinforce each other and tend to push child labor upwards.

\section{Uncertainty in returns to education}

\subsection{Measuring uncertainty}

\footnotetext{
${ }^{11} \mathrm{We}$ are grateful to the editor for bringing this point to our attention.

${ }^{12}$ It is not straightforward to provide an efficiency analysis of those expenditures, since this requires a more thorough understanding of the impact of mortality on utility: the question is to some extent analogous to the question of optimal population, for which we know that no simple answers can be given (see e.g. Blackorby et al. (1995)).
} 
As we have discussed in Section 1, mortality risk is not the only source of uncertainty in education investment. Returns to education are also intrinsically uncertain because of unpredictable future labor market conditions or unknown abilities. To compare the relative importance of these two sources of uncertainty, we need a measure of the unpredictable risk associated with future earnings.

The Mincer equation (Mincer (1974)) provides an estimation of the returns to schooling by regressing the logarithm of the wage rate on years of schooling and other control variables. In this equation, the estimated coefficient for years of schooling reflects the average percentage increase in wages due to an additional year of schooling. It is thus a measure of the mean return to education. The standard error of the estimator provides a measure of the variation of the returns to education among individuals. In order to measure uncertainty in the returns to education, we therefore use the coefficient of variation of the estimator associated with years of education in the Mincer equation. This measure may be biased upwards since the estimation residuals used to calculate the standard error also reflect the presence of measurement errors, misspecification of the model or unobservable variables. However, as emphasized by Cunha et al. (2005), it is possible to disentangle heterogeneity (an unobservable to the econometrician but not to the decision-maker) from unforecastable uncertainty. Moreover, as stressed by Ashenfelter et al. (1999), there is a publication bias in favor of significant estimates, so that estimation results with large uncertainty may be under-represented. There may thus also be a counteracting downwards bias in our measure of uncertainty (since the coefficient of variation is simply the inverse of the t-ratio).

Ashenfelter et al. (1999)'s survey of the literature on returns to education reports 96 different returns to schooling obtained from 27 studies using data from 1974 to 1995. The average coefficient of variation of the education estimator across the OLS estimates is equal to $9 \%^{13}$. Using data from US college students, Cunha et al. (2005) show that about $60 \%$ of variability in returns to schooling is forecastable. Applied to the estimate above, this leaves us with a measure of the unforecastable uncertainty of about $3.6 \%$.

Using Indonesian data, Duflo (2001) obtains that one additional year of edu-

\footnotetext{
${ }^{13}$ In the context of Mincer equation estimation, ordinary least squares (OLS) estimates are known to be biased due to unobservable variables, such as ability, that are part of the residuals and correlated with schooling. One approach to solve this endogeneity problem consists in applying two-stage least squares (2SLS). The standard errors of the 2SLS estimation are consistently larger than the ones from OLS regression yielding a coefficient of variation of $28 \%$ in Ashenfelter et al. (1999). However it is unclear whether these standard errors really reflect uncertainty or are just a consequence of the instrumental variable technique. Moreover, it is also not clear that we should rely here on the 2SLS estimates since many of the unobserved characteristics underlying the endogeneity bias are known by the parent when taking the educational decision.
} 
cation increases earnings by $8 \%$. The coefficient of variation is low for her OLS estimates, around 1\%, which gives a measure of unforecastable uncertainty of about $0.4 \%$. This can be compared to the young adult mortality rate in Indonesia which is $6.3 \%$. According to Bedi and Gaston (1999), the estimated returns to education in Honduras are $6 \%$ (using OLS) with a coefficient of variation of $8 \%$. Again correcting for predictability, intrinsic uncertainty is equal to $3.2 \%$. This is much smaller than the adult mortality risks which averages $8.8 \%$ in Honduras. ${ }^{14}$ One can therefore conclude from the empirical studies that mortality risks are probably more important than intrinsic uncertainty in the risks associated with schooling decisions. This is even more important in Sub-Saharan Africa, where mortality risks are much higher than those in Indonesia or Honduras.

\subsection{Child labor and uncertainty}

We extend the basic model to integrate uncertainty in the returns to education, along the lines proposed by Pouliot (2006). If returns to education are risky, a child's consumption level, $c_{c}$, is given by

$$
c_{c}=\Delta h\left(1-l_{c}\right)+b-\tau,
$$

where $\Delta$ is an absolutely continuous random variable with positive support and $E(\Delta)=1$. We write the expected utility of a child as:

$$
\begin{aligned}
W_{c} & =E\left[V\left(c_{c}\right)\right]+\lambda\left[U\left(c_{2}^{a}\right)+\delta W_{c}\right] \\
& =\frac{E\left[V\left(c_{c}\right]\right)+\lambda U\left(c_{2}^{a}\right)}{1-\delta \lambda},
\end{aligned}
$$

and the expected utility of the parent as:

$$
W_{p}=U\left(c_{1}\right)+\frac{p U\left(c_{2}^{a}\right)}{1-\delta \lambda}+(1-p) U\left(c_{2}^{d}\right)+\frac{p \delta E\left[V\left(c_{c}\right)\right]}{1-\delta \lambda} .
$$

In the second period, the child maximizes (31) with respect to $\tau$ conditional on $l_{c}$ and $s$, which yields the following first-order conditions:

$$
\begin{aligned}
& E\left[V^{\prime}\left(c_{c}\right)\right]=\lambda U^{\prime}\left(c_{2}^{a}\right) \quad \text { and } \quad \tau>0, \\
& E\left[V^{\prime}\left(c_{c}\right)\right]>\lambda U^{\prime}\left(c_{2}^{a}\right) \text { and } \tau=0 .
\end{aligned}
$$

\footnotetext{
${ }^{14}$ In both studies, if we consider the standard errors of the 2SLS estimation, we obtain coefficients of variation between $20 \%$ and $40 \%$, and unforecastable uncertainties between $8 \%$ and $16 \%$. However, as discussed before, these probably reflect the use of instruments more than uncertainty.
} 
The parent maximizes (32). The first-order conditions with respect to $b, l_{c}$, and $s$ are, respectively:

$$
\begin{gathered}
U^{\prime}\left(c_{2}^{a}\right)=\delta E\left[V^{\prime}\left(c_{c}\right)\right] \quad \text { and } \quad b>0 \\
U^{\prime}\left(c_{2}^{a}\right)>\delta E\left[V^{\prime}\left(c_{c}\right)\right] \quad \text { and } \quad b=0 \\
U^{\prime}\left(c_{1}\right)+p \frac{U^{\prime}\left(c_{2}^{a}\right)}{1-\delta \lambda} \frac{d \tau}{d l_{c}}=p \frac{\delta E\left[V^{\prime}\left(c_{c}\right) \Delta h^{\prime}\left(1-l_{c}\right)\right]}{1-\delta \lambda}+p \frac{\delta E\left[V^{\prime}\left(c_{c}\right)\right]}{1-\delta \lambda} \frac{d \tau}{d l_{c}} \text { and } \tau>0 \\
U^{\prime}\left(c_{1}\right)=p \frac{\delta E\left[V^{\prime}\left(c_{c}\right) \Delta h^{\prime}\left(1-l_{c}\right)\right]}{1-\delta \lambda} \quad \text { and } \quad \tau=0 \\
U^{\prime}\left(c_{1}\right)+p \frac{\delta E\left[V^{\prime}\left(c_{c}\right)\right]}{1-\delta \lambda} \frac{d \tau}{d s}=p \frac{U^{\prime}\left(c_{2}^{a}\right)}{1-\delta \lambda}\left[1+\frac{d \tau}{d s}\right]+(1-p) U^{\prime}\left(c_{2}^{d}\right) \quad \text { and } \quad \tau>0 \\
U^{\prime}\left(c_{1}\right)=p \frac{U^{\prime}\left(c_{2}^{a}\right)}{1-\delta \lambda}+(1-p) U^{\prime}\left(c_{2}^{d}\right) \quad \text { and } \quad \tau=0
\end{gathered}
$$

As in Pouliot (2006), uncertainty in the returns to education increases the level of child labor in all cases. When parental transfers are positive, combining (35), (38), and (40), we obtain:

$$
p h^{\prime}\left(1-l_{c}\right)=p \frac{E\left[V^{\prime}\left(c_{c}\right)\right]}{\operatorname{Cov}\left[V^{\prime}\left(c_{c}\right), \Delta\right]+E\left[V^{\prime}\left(c_{c}\right)\right]}+(1-p) \frac{U^{\prime}\left(c_{2}^{d}\right)}{\frac{\delta\left[\operatorname{Cov}\left[V^{\prime}\left(c_{c}\right), \Delta\right]+E\left[V^{\prime}\left(c_{c}\right)\right]\right]}{1-\delta \lambda}}
$$

Since $c_{c}$ increases with $\Delta, \operatorname{Cov}\left[V^{\prime}\left(c_{c}\right), \Delta\right]<0$, and uncertainty in the returns from education increases the level of child labor. However, we know from Proposition 4 that, in the absence of uncertainty, the level of child labor is inefficiently low so that uncertainty in returns potentially offsets the effect of lifetime uncertainty. Thus, if $\delta \frac{\operatorname{Cov}\left[V^{\prime}\left(c_{c}\right), \Delta\right]}{1-\delta \lambda}=(1-p)\left[U^{\prime}\left(c_{2}^{d}\right)-\frac{U^{\prime}\left(c_{2}^{a}\right)}{1-\delta \lambda}\right]$, the two effects cancel out, and the equilibrium level of child labor is efficient. ${ }^{15}$

When filial transfers are positive, the same result can be obtained under some additional restrictions on the third-derivative of $V\left(c_{c}\right)$. We provide the proof in the Appendix B.

\footnotetext{
${ }^{15}$ Obviously, if $\delta \frac{\operatorname{Cov}\left[V^{\prime}\left(c_{c}\right), \Delta\right]}{1-\delta \lambda}<(1-p)\left[U^{\prime}\left(c_{2}^{d}\right)-\frac{U^{\prime}\left(c_{2}^{a}\right)}{1-\delta \lambda}\right]$, the resulting level of child labor is inefficiently high.
} 


\section{Efficiency-restoring policy interventions in the old- age security model}

In Section 3, we have shown that, in the absence of insurance markets, parents may choose an inefficiently high or low level of child labor depending on the levels of parental and filial altruism. In this section, we focus on the situation where filial transfers are positive, and $\delta \lambda<\frac{1}{2}$. As discussed by Nugent (1985), in many developing countries, filial transfers and the old-age security motive play a major role for fertility or education decisions (see for instance Cain (1982), DeVos (1985), Lillard and Willis (1997) and Jensen (2004)) . Moreover, African countries in which early mortality is really an issue are also characterized by impressively high levels of filial transfers (see e.g., Caldwell and Caldwell, 1987). In this section, we discuss some policy interventions that can potentially restore efficiency in this setting.

A tax schedule that replicates the insurance scheme would obviously be efficiencyenhancing. But, as much as an insurance contract, such a direct scheme might not be implementable. Public pension is potentially an attractive alternative policy, since we have shown that inefficient levels of child labor are related to the old-age security motive. The introduction of a fully-funded public pension has no impact, given that we have already assumed perfect capital markets. However, a pay-as-you-go pension system provides insurance to parents since it constitutes a transfer from surviving children to all parents and may restore efficiency. ${ }^{16}$

Another alternative is to introduce cash transfers conditional on child's education. Such conditional cash transfers are increasingly popular in developing countries, as attested by the Bolsa Escola program in Brazil or PROGRESA in Mexico (see e.g., Ravallion and Wodon, 2000). The conditional cash transfer distorts incentives in favor of the child's education, while simultaneously compensating poor families for foregone child labor earnings. Consider that a parent receives in period 1 a cash transfer proportional to the amount of education he provides to his child, $1-l_{c}$. We let this transfer be financed by a tax on surviving children in period 2 . The tax is uniform and depends on the average level of education in the economy (we assume that the economy is populated by a large number of individuals) ${ }^{17}$. We can then show:

Proposition 5. If the level of child labor is inefficiently high, there always exists a

\footnotetext{
${ }^{16}$ Jensen (2004) shows that the extension of public pensions to the black population in South Africa significantly reduced the amount of private transfers from children: one rand of public transfers reduced private transfers by about 0.30 rands.

${ }^{17}$ Note that our results do not change if we consider alternative financing mechanisms, such as a tax levied on the parents' first or second period income or a budget deficit. These schemes have no impact on the parental decision but only on the net income levels of the agents.
} 
cash transfer program conditional on the level of education, financed by a uniform tax, that restores efficiency in the equilibrium level of child labor.

Proof. The parent's first period budget constraint becomes

$$
c_{1}=A+l_{c}-s+\theta\left(1-l_{c}\right)
$$

where $\theta$ represents the transfer per unit of education provided. In period 2, the parents' budget constraints are as before given by equations (2) and (3). Let $\overline{1-l_{c}}$ represent the average level of education in the economy. Under a balanced budget constraint, the tax we need to impose on surviving children in period 2 is equal to $\left(\theta\left(\overline{1-l_{c}}\right) / p\right)$, so that the child's budget constraint in period 2 is now given by

$$
c_{c}=h\left(1-l_{c}\right)-\tau-\theta\left(\overline{1-l_{c}}\right) / p
$$

The first-order condition with respect to $l_{c}$ is now given by:

$$
U^{\prime}\left(c_{1}\right)(1-\theta)+p \frac{U^{\prime}\left(c_{2}^{a}\right)}{1-\delta \lambda} \frac{d \tau}{d l_{c}}=p \frac{\delta V^{\prime}\left(c_{c}\right)}{1-\delta \lambda}\left[h^{\prime}\left(1-l_{c}\right)+\frac{d \tau}{d l_{c}}\right]
$$

Combining equations (10), (15), (19), (20), and (42), one gets:

$$
p h^{\prime}\left(1-l_{c}\right)=(1-\theta)\left[p+(1-p) \frac{\lambda U^{\prime \prime}\left(c_{2}^{a}\right)+V^{\prime \prime}\left(c_{c}\right)}{\delta \lambda^{2} U^{\prime \prime}\left(c_{2}^{a}\right)+V^{\prime \prime}\left(c_{c}\right)} \frac{U^{\prime}\left(c_{2}^{d}\right)}{\frac{U^{\prime}\left(c_{2}^{a}\right)}{1-\delta \lambda}}\right]
$$

If $\theta=0$, we find the initial equilibrium given by equation (21). If $\theta=1$, the cash transfer is such that parents choose $l_{c}=0$. Given our assumptions on $U$ and $V$, the level of child labor defined by equation (43) is a continuous function of $\theta$. As a result, there always exists a level of $\theta$ that implements the efficient level of child labor.

As a result, an appropriate system of conditional cash transfers can always bring back the efficient level of child labor. It should however be noted that global efficiency is not achieved, as decisions over savings and transfers are typically inefficient. In the case where child labor is inefficiently low (such as occurs with positive bequests), conditional transfers can also be used to restore efficiency by taxing education and giving lump sum subsidies to parents.

Finally, following our discussion in Section 4, one may wonder whether public policies should give priority to health or education. While our model does not allow us to provide a clear answer to this question, important indirect effects are at work under both policies: on the one hand, better health reduces premature mortality and increases returns to education, thereby inducing parents to invest more in education; on the other hand, mandatory schooling increases parental incentives to invest in their child's health. These indirect effects cannot be ignored in the evaluation of the policies. 


\section{Conclusion}

In this paper we have investigated the impact of young adult mortality on child labor and educational decisions. This particular type of risk fundamentally differs in its impact from uncertain returns to education. As with uncertain returns to education, mortality risks tend to make education less attractive in the absence of appropriate insurance mechanisms. However, mortality risks also affect the set of possible transfers in the future by changing the number of individuals between whom those transfers are made. As a result, parents future utility is affected by this uncertainty, which in turn affects their current decisions such as savings or child labor. This is all the more important that young adult mortality risks, which can reach $50 \%$ in Sub Saharan Africa, tend to be much higher than the intrinsic uncertainty associated with returns to education.

With mortality risks, the level of child labor is inefficient. The presence of transfers between children and parents does not allow parents to correctly internalize the negative impact of child labor on their children's future earnings. Child labor is too high if parental altruism is low and parents anticipate positive transfers from their children in the future. The uncertainty affecting the future transfers induces parents to increase child labor in order to save more in the current period and enjoy a larger certain income in the future. Parental altruism reduces child labor, but child labor can then be inefficiently low when altruism is too high or when parents expect to give positive transfers to their children in the future. Being unsure about the number of children who will be alive then, the parent chooses to reduce his intended bequest, save less and invest more in the contingent transfer, which is education.

In areas characterized by high adult mortality and large filial transfers, child labor is thus too high. As we also show, child labor is even higher if capital markets are imperfect, or returns to education are uncertain. However, when the level of child labor is inefficiently high, a cash transfer program conditional on child's schooling can always restore efficiency regarding child labor. Lastly, if mortality is endogenous, for instance because parents can choose the level of health expenditures they incur for their children, mortality tends to be too high, which depresses returns to education and further increases child labor. A public health policy which reduces mortality may contribute to reduce child labor by inducing parents to invest more in education. 


\section{A Proof of Proposition 2}

\section{A.1 Parental transfers}

We concentrate in the case in which parental transfers are positive and so filial transfers are nil.

Proof. The first-order conditions are given by equations (13), (9), and (11). These equations then define three implicit equations, namely:

$$
\begin{aligned}
& F_{1}\left(b, l_{c}, s ; p, \lambda, \delta\right)=\delta V^{\prime}\left(h\left(1-l_{c}\right)+b\right)-U^{\prime}(A+s-b)=0 \\
& F_{2}\left(b, l_{c}, s ; p, \lambda, \delta\right)=U^{\prime}\left(A+l_{c}-s\right)-p \frac{\delta V^{\prime}\left(h\left(1-l_{c}\right)+b\right)}{1-\delta \lambda} h^{\prime}\left(1-l_{c}\right)=0 \\
& F_{3}\left(b, l_{c}, s ; p, \lambda, \delta\right)=-U^{\prime}\left(A+l_{c}-s\right)+p \frac{U^{\prime}(A+s-b)}{1-\delta \lambda}+(1-p) U^{\prime}(A+s)=0
\end{aligned}
$$

From the implicit function theorem, we know that:

$$
\left(\begin{array}{c}
\frac{d b}{d p} \\
\frac{d l_{c}}{d p} \\
\frac{d s}{d p}
\end{array}\right)=-\left(\begin{array}{ccc}
\frac{\partial F_{1}}{\partial b} & \frac{\partial F_{1}}{\partial l_{c}} & \frac{\partial F_{1}}{\partial s} \\
\frac{\partial F_{2}}{\partial b} & \frac{\partial F_{2}}{\partial l_{c}} & \frac{\partial F_{2}}{\partial s} \\
\frac{\partial F_{3}}{\partial b} & \frac{\partial F_{3}}{\partial l_{c}} & \frac{\partial F_{3}}{\partial s}
\end{array}\right)^{-1}\left(\begin{array}{c}
\frac{\partial F_{1}}{\partial p} \\
\frac{\partial F_{2}}{\partial p} \\
\frac{\partial F_{3}}{\partial p}
\end{array}\right)
$$

Applying it to the implicit equations (44), (45), and (46), we obtain:

$$
\begin{aligned}
& -\left(\begin{array}{ccc}
\delta V^{\prime \prime}\left(c_{c}\right)+U^{\prime \prime}\left(c_{2}^{a}\right) & -\delta V^{\prime \prime}\left(c_{c}\right) h^{\prime} & -U^{\prime \prime}\left(c_{2}^{a}\right) \\
-p \frac{\delta V^{\prime \prime}\left(c_{c}\right)}{1-\delta \lambda} h^{\prime} & U^{\prime \prime}\left(c_{1}\right)+p \frac{\delta V^{\prime \prime}\left(c_{c}\right)}{1-\delta \lambda}\left[h^{\prime}\right]^{2}+p \frac{\delta V^{\prime}\left(c_{c}\right)}{1-\delta \lambda} h^{\prime \prime} & -U^{\prime \prime}\left(c_{1}\right) \\
-p \frac{U^{\prime \prime}\left(c_{2}^{a}\right)}{1-\delta \lambda} & -U^{\prime \prime}\left(c_{1}\right) & U^{\prime \prime}\left(c_{1}\right)+p \frac{U^{\prime \prime}\left(c_{2}^{a}\right)}{1-\delta \lambda}+(1-p) U^{\prime \prime}\left(c_{2}^{d}\right)
\end{array}\right) \\
& \cdot\left(\begin{array}{c}
0 \\
-\delta V^{\prime}\left(c_{c}\right) h^{\prime} \\
\frac{U^{\prime}\left(c_{2}^{a}\right)}{1-\delta \lambda}-U^{\prime}\left(c_{2}^{d}\right)
\end{array}\right) \\
& .
\end{aligned}
$$

The determinant of this matrix is negative due to the concavity of this problem. Thus we can express $\frac{d l_{c}}{d p}$ as: 


$$
\begin{aligned}
\frac{d l_{c}}{d p} & =\left\{\left[\delta V^{\prime \prime}\left(c_{c}\right)+U^{\prime \prime}\left(c_{2}^{a}\right)\right]\left[U^{\prime \prime}\left(c_{1}\right)+p \frac{U^{\prime \prime}\left(c_{2}^{a}\right)}{1-\delta \lambda}+(1-p) U^{\prime \prime}\left(c_{2}^{d}\right)\right]-p \frac{\left[U^{\prime \prime}\left(c_{2}^{a}\right)\right]^{2}}{1-\delta \lambda}\right\}\left[-\frac{\delta V^{\prime}\left(c_{c}\right)}{1-\delta \lambda} h^{\prime}\left(1-l_{c}\right)\right] \\
& -\left\{\left[\delta V^{\prime \prime}\left(c_{c}\right)+U^{\prime \prime}\left(c_{2}^{a}\right)\right]\left[-U^{\prime \prime}\left(c_{1}\right)\right]-U^{\prime \prime}\left(c_{2}^{a}\right)\left[p \frac{\delta V^{\prime \prime}\left(c_{c}\right)}{1-\delta \lambda} h^{\prime}\left(1-l_{c}\right)\right]\right\}\left[\frac{U^{\prime}\left(c_{2}^{a}\right)}{1-\delta \lambda}-U^{\prime}\left(c_{2}^{d}\right)\right] \\
& =\left\{\left[\delta V^{\prime \prime}\left(c_{c}\right)+U^{\prime \prime}\left(c_{2}^{a}\right)\right]\left[U^{\prime \prime}\left(c_{1}\right)+(1-p) U^{\prime \prime}\left(c_{2}^{d}\right)\right]+p \frac{U^{\prime \prime}\left(c_{2}^{a}\right)}{1-\delta \lambda} \delta V^{\prime \prime}\left(c_{c}\right)\right\}\left[-\frac{\delta V^{\prime}\left(c_{c}\right)}{1-\delta \lambda} h^{\prime}\left(1-l_{c}\right)\right] \\
& +\left\{\left[\delta V^{\prime \prime}\left(c_{c}\right)+U^{\prime \prime}\left(c_{2}^{a}\right)\right] U^{\prime \prime}\left(c_{1}\right)+U^{\prime \prime}\left(c_{2}^{a}\right)\left[p \frac{\delta V^{\prime \prime}\left(c_{c}\right)}{1-\delta \lambda} h^{\prime}\left(1-l_{c}\right)\right]\right\}\left[\frac{U^{\prime}\left(c_{2}^{a}\right)}{1-\delta \lambda}-U^{\prime}\left(c_{2}^{d}\right)\right]
\end{aligned}
$$

Combining (45) and (46) we obtain:

$$
\frac{\delta V^{\prime}\left(c_{c}\right)}{1-\delta \lambda} h^{\prime}\left(1-l_{c}\right)=\frac{U^{\prime}\left(c_{2}^{a}\right)}{1-\delta \lambda}+\frac{1-p}{p} U^{\prime}\left(c_{2}^{d}\right)
$$

Replacing (49) into (48), combining it with (22) and simplifying the resulting equation, we obtain

$$
\begin{aligned}
\frac{d l_{c}}{d p} & =-p U^{\prime}\left(c_{2}^{d}\right) U^{\prime \prime}\left(c_{2}^{a}\right) \frac{\delta V^{\prime \prime}\left(c_{c}\right)}{1-\delta \lambda}-(1-p) \frac{\left[U^{\prime}\left(c_{2}^{d}\right)\right]^{2}}{U^{\prime}\left(c_{2}^{a}\right)} U^{\prime \prime}\left(c_{2}^{a}\right) \delta V^{\prime \prime}\left(c_{c}\right) \\
& -\frac{1}{p} U^{\prime}\left(c_{2}^{d}\right)\left[U^{\prime \prime}\left(c_{1}\right) \delta V^{\prime \prime}\left(c_{c}\right)+U^{\prime \prime}\left(c_{1}\right) U^{\prime \prime}\left(c_{2}^{a}\right)\right] \\
& -\left[\frac{U^{\prime}\left(c_{2}^{a}\right)}{1-\delta \lambda}-\frac{1-p}{p} U^{\prime}\left(c_{2}^{d}\right)\right]\left[(1-p) U^{\prime \prime}\left(c_{2}^{d}\right) \delta V^{\prime \prime}\left(c_{c}\right)+(1-p) U^{\prime \prime}\left(c_{2}^{d}\right) U^{\prime \prime}\left(c_{2}^{a}\right)\right]<0
\end{aligned}
$$

The case of filial transfers can be obtained upon request from the authors.

\section{B Uncertainty in the returns to education with filial transfers}

Differentiating equation (33) with respect to $l_{c}$ and $s$ yields respectively:

$$
\begin{aligned}
\frac{d \tau}{d l_{c}} & =\frac{-h^{\prime}\left(1-l_{c}\right) E\left[V^{\prime \prime}\left(c_{c}\right) \Delta\right]}{\lambda U^{\prime \prime}\left(c_{2}^{a}\right)+E\left[V^{\prime \prime}\left(c_{c}\right)\right]} \\
\frac{d \tau}{d s} & =\frac{-\lambda U^{\prime \prime}\left(c_{2}^{a}\right)}{\lambda U^{\prime \prime}\left(c_{2}^{a}\right)+E\left[V^{\prime \prime}\left(c_{c}\right)\right]}
\end{aligned}
$$

By definition:

$$
\begin{gathered}
\operatorname{Cov}\left[V^{\prime}\left(c_{c}\right), \Delta\right]=E\left[V^{\prime}\left(c_{c}\right) \Delta\right]-E\left[V^{\prime}\left(c_{c}\right)\right] \\
\operatorname{Cov}\left[V^{\prime \prime}\left(c_{c}\right), \Delta\right]=E\left[V^{\prime \prime}\left(c_{c}\right) \Delta\right]-E\left[V^{\prime \prime}\left(c_{c}\right)\right]
\end{gathered}
$$


since $E[\Delta]=1$. Due to the concavity of $V\left(c_{c}\right), \operatorname{Cov}\left[V^{\prime}\left(c_{c}\right), \Delta\right]<0$. In order to sign $\operatorname{Cov}\left[V^{\prime \prime}\left(c_{c}\right), \Delta\right]$, we need to make an assumption on the sign of the third derivative of $V\left(c_{c}\right)$. In what follows, we assume that $V^{\prime \prime \prime}\left(c_{c}\right)>0^{18}$, which implies $\operatorname{Cov}\left[V^{\prime \prime}\left(c_{c}\right), \Delta\right]>0$

Replacing (51) into (37), then (52) into (39) and simplifying the resulting equation using (33), (53), and (54), we obtain:

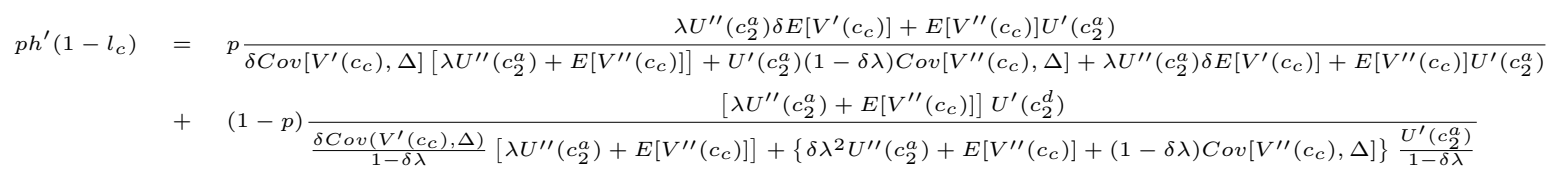

With the assumptions made above, equation (55) implies that uncertainty in the returns to education further increases the level of child labor in the case of filial transfers.

\section{References}

Ashenfelter, O., Harmon, C., and Oosterbeek, H. (1999). A review of estimates of the schooling/ earnings relationship, with tests for publication bias. Labour Economics, 6(4):453-470.

Baland, J. M. and Robinson, J. A. (2000). Is child labor inefficient. Journal of Political Economy, 108(4):663-679.

Basu, K. and Van, P. H. (1998). The economics of child labor. The American Economic Review, 88(3):412-427.

Becker, G. S. (1964). Human Capital: A Theoretical and Empirical Analysis, with Special Reference to Education. Columbia university press. National Bureau of Economic Research, New York, 1st edition.

Bedi, A. S. and Gaston, N. (1999). Using variation in schooling availability to estimate educational returns for honduras. Economics of Education Review, 18(1):107-116.

Blackorby, C., Bossert, W., and Donaldson, D. (1995). Intertemporal population ethics: Critical-level utilitarian principles. Econometrica, 63(6):1303-1320.

Cain, M. (1982). Perspectives on family and fertility in developing countries. Population Studies, 36(2):159-175.

\footnotetext{
${ }^{18}$ A positive third derivative of the utility function is defined as 'prudence' in decision theory, see e.g. Kimball (1990).
} 
Caldwell, J. C. and Caldwell, P. (1987). The cultural context of high fertility in sub-saharan africa. Population and Development Review, 13(3):409-437.

Cunha, F., Heckman, J., and Navarro, S. (2005). Separating uncertainty from heterogeneity in life cycle earnings. Oxford Economic Papers, 57(2):191-261.

DeVos, S. (1985). An old-age security incentive for children in the philippines and taiwan. Economic Development and Cultural Change, 33(4):793-814.

Duflo, E. (2001). Schooling and labor market consequences of school construction in indonesia: Evidence from an unusual policy experiment. The American Economic Review, 91(4):795-813.

Edmonds, E. V. (2006). Child labor and schooling responses to anticipated income in south africa. Journal of Development Economics, 81(2):386-414.

Eswaran, M. (2000). Institutions, Incentives and Economic Reforms in India, chapter 9, pages 267-296. Sage India.

Hazan, M. and Zoabi, H. (2006). Does longevity cause growth? a theoretical critique. Journal of Economic Growth, 11(4):363-376.

Jensen, R. T. (2004). Do private transfers 'displace' the benefits of public transfers? evidence from south africa. Journal of Public Economics, 88(1-2):89-112.

Kimball, M. (1990). Precautionary saving in the small and in the large. Econometrica, 58(1):53-73.

Levhari, D. and Weiss, Y. (1974). The effect of risk on the investment in human capital. The American Economic Review, 64(6):950-963.

Lillard, L. A. and Willis, R. J. (1997). Motives for intergenerational transfers: Evidence from malaysia. Demography, 34(1):115-134.

Mincer, J. (1974). Schooling, experience, and earnings. National bureau of economic research. New York (N.Y.): Columbia university press.

Nugent, J. B. (1985). The old-age security motive for fertility. Population and Development Review, 11(1):75-97.

Pouliot, W. (2006). Introducing uncertainty into baland and robinson's model of child labour. Journal of Development Economics, 79(1):264-272.

Ravallion, M. and Wodon, Q. (2000). Does child labour displace schooling? evidence on behavioural responses to an enrollment subsidy. The Economic Journal, 110:C158-C175. 
Razin, A. (1976). Lifetime uncertainty, human capital and physical capital. Economic Inquiry, 14(3):439-448.

Strulik, H. (2004). Child mortality, child labour and economic development. The Economic Journal, 114(497):547-568. 